\title{
The Collegiate Hackathon Experience
}

\author{
Brittany Ann Kos \\ ATLAS Institute \\ College of Engineering and Applied Sciences \\ University of Colorado Boulder \\ brittany.kos@colorado.edu
}

\begin{abstract}
Collegiate hackathons are marathon-style, project building competitions where students can learn computing in an informal environment, build community, network with members of the technology industry, and be more productive members of the workforce. I am interested in understanding the social climate of hackathons and how it affects hackathon participants, particularly women and nonbinary students, who only make up $23 \%$ of collegiate hackathon attendees. I will be exploring two lines of inquiry: (1) to explore the experiences of hackathon attendees to gain a deeper understanding about why participants do (or do not) participate in hackathons, what motivates them to attend, and what engages them at these events; and (2) to explore the ways collegiate hackathons can adapt their design practices to create an inclusive and equitable events for marginalized and minority students.
\end{abstract}

\section{CCS CONCEPTS}

-Social and professional topics $\rightarrow$ Informal education; Women;

\section{KEYWORDS}

collegiate hackathon; informal learning; gender; women; nonbinary ACM Reference Format:

Brittany Ann Kos. 2018. The Collegiate Hackathon Experience. In ICER '18: 2018 International Computing Education Research Conference, August 13-15, 2018, Espoo, Finland. ACM, New York, NY, USA, 2 pages. https://doi.org/10. $1145 / 3230977.3231022$

\section{PROGRAM CONTEXT}

I am beginning the sixth and final year of my Ph.D. studies of an interdisciplinary degree program at the University of Colorado Boulder. This program has allowed me to combine my CS background with research methodologies and perspectives from multiple disciplines, including Computer Science, Education, the Learning Sciences, and Information Science.

\section{CONTEXT AND MOTIVATION}

Collegiate hackathons are informal learning environments where teams of college students build computing projects competitively. The events are 24 or 36 hours long and held on weekends at college campuses. Collegiate hackathons have been growing in popularity

Permission to make digital or hard copies of part or all of this work for personal or classroom use is granted without fee provided that copies are not made or distributed for profit or commercial advantage and that copies bear this notice and the full citation on the first page. Copyrights for third-party components of this work must be honored

For all other uses, contact the owner/author(s).

ICER '18, August 13-15, 2018, Espoo, Finland

(c) 2018 Copyright held by the owner/author(s).

ACM ISBN 978-1-4503-5628-2/18/08.

https://doi.org/10.1145/3230977.3231022 over the last decade and are becoming more popular as the computing field grows in size and demand. In the 2016-2017 school year, over 200 collegiate hackathons were hosted in North America and Europe and over 65,000 students participated in these events [6]. These events are largely attended by computer science (CS) undergraduates [6] and many students go to these events to learn skills and practices of the computing field $[1,5]$, build community with fellow students and work on projects with friends [7, 10], networking with mentors and sponsors within the technology industry $[1,8]$, and become better prepared for the workforce and industry hackathons [4].

Despite the benefits that hackathons offer, we still see a disproportionate number of white and Asian men attending these events over women, non-binary students, and non-Asian students of color [6]. Collegiate hackathons can create an environment where marginalized students feel disinterested in attending or unwelcome at the events. I am interested in understanding the social climate of hackathons and how it affects hackathon participants, particularly women and non-binary students. I will explore two lines of inquiry: (1) to gain a deeper understanding about why participants do (or do not) participate in hackathons, what motivates them to attend, and what engages them at these events; and (2) to explore the design of hackathons with the end goal of creating inclusive and equitable events for all students.

\section{BACKGROUND \& RELATED WORK}

There is a small, but growing body of work done on collegiate hackathons. Current work shows that collegiate hackathons are sites of informal learning $[5,8,10]$ that impact students' perceptions of computing $[9,10]$ and may impact their retention in CS [7]. However there are hardly any studies about student experiences at these events, particularly women and non-binary students [10]. Overall, collegiate hackathons report that $23 \%$ [6] of their participants are female or non-binary and non-collegiate hackathons report that as little as $10 \%$ of their participants are female [3]. A handful of studies have researched why this gender gap exists and they have made some design recommendations for building events that are more inclusive for women. There is also an effort from the community of collegiate hackathon organizers across the US and Europe to build more diverse events, which includes changing design practices to be more inclusive as well as hosting female and non-binary focused collegiate hackathons. My work is positioned within these diversity and inclusion efforts and seeks to expand our understanding of hackathon attendees and build more equitable environments for all students. My dissertation will explore three lines of inquiry that build on the previous studies and add to the body of collegiate hackathon literature. 


\section{RESEARCH PROBLEM, GOALS \& METHODS}

This work is guided by two motivating questions: (1) what types of experiences do attendees (and non-attendees) have with collegiate hackathons; and (2) how can we design collegiate hackathons to be more inclusive and equitable for more types of students? I have three lines of inquiry that explore these motivating questions.

Study \#1 will be a retrospective, design-based research project about the design of a female-focused hackathon called T9Hacks. Four years ago I founded T9Hacks and have worked as the lead event organizer for three iterations of T9Hacks events. While planning T9Hacks, my team and I were influenced by our experiences attending collegiate hackathons and a desire to create an inclusive event, we also tried to mimic best practices that we knew created equitable and welcoming environments for women in computing, all while trying to work within a standard collegiate hackathon model that was set by one of our event partners, Major League Hacking (MLH). I chose a design-based research study [2] because it is research that is conducted in real-life, ongoing contexts where the researcher is involved in the design of the project; these studies often result in producing theories that richly describe participant experiences and produce interventionist designs that iteratively improve the research context. This study has two goals: (1) to explore how the design practices of T9hacks changed over four years; and (2) to show the tension between "scholarly" hackathon design recommendations and what the organizing team wants to do. By performing a retrospective analysis on my team's decision-making process, we can look at which design elements were the most impactful for students as well as what was resources were available or influential to the organizing team.

Study \#2 is a two-part exploratory study that provides insight into the experiences of female-focused collegiate hackathon attendees. The first part of this study studies hackathon participants' sense of community at three types of hackathons: women-only (where only women and non-binary students are the focus and only they are allowed to attend), female-focused (here there is a focus on female and non-binary students, but students of all genders can attend), and traditional events (where there is no gender focus at the hackathon and all students can attend). The second part of this study explores the goals participants had and the different ways they engaged at T9Hacks. Findings show that students were motivated in attending T9Hacks for different reasons, had worked with other participants in multiple ways, and had different motivations for attending workshops. This study also shows how the design of the can support or restrict the trajectories these different students. These findings are important since they contradict the traditional hackathon narrative that researchers and popular student hackathon guides have provided in the past. These findings can inform future hackathons and show additional ways hackathons can be designed to be inclusive of different types of students.

Study \#3 is under design. I hope to use the feedback from the ICER Doctoral Consortium to finalize the details of this study, since engaging in the ICER DC will allow me to better understand how my research can provide insight and value to the CS Education community. This study builds on Study \#2 findings and delves deeper into participants' motivations and engagement with collegiate hackathons. This study will be a multi-part mixed-methods study. The first part of the study will be an intervention and designbased study of T9Hacks. I will be implementing design changes to the event that build inclusive events for the different types of participants found in Study \#2. Another part of the study will be exploring how these design changes did (or did not) affect the hackathon participants. I intend to interview hackathon participants and nonparticipants to gain a deeper understanding of their experiences with collegiate hackathons and what pieces of the hackathon were most impactful or influential to them. The results will be used to gain a deeper understanding of female-focused hackathon participants and to suggest inclusive design practices that can be used at other collegiate hackathons.

\section{DISSERTATION STATUS}

My Ph.D. program requires students to complete three exams: Preliminary Exam, Comprehensive Exam (where a student becomes a candidate), and the final Dissertation Defense. I have completed the Preliminary Exam and will be completing the Comprehensive Exam in May of 2018. For my dissertation, I proposed three studies; Study \#1 will be complete in Summer 2018, Study \#2 is complete, and Study \#3 will begin in Fall of 2018, after the ICER DC. I have a working outline for my dissertation and I will begin writing in Summer 2018. Completion of all dissertation work is anticipated for Spring of 2019.

\section{EXPECTED CONTRIBUTIONS}

My research and findings will be used to inform the design practices of collegiate hackathons and to create inclusive and equitable environments. Broadening participation at collegiate hackathons will allow all students to have the opportunity to engage in these events, learn computing in an informal environment, build community, network with members of the technology industry, and be more productive members of the workforce. Designing inclusive and equitable collegiate hackathons will benefit all students, but may have the most impact on female and non-binary students. Findings may also inform the design of industry hackathons and other informal learning environments.

\section{REFERENCES}

[1] C. Anslow, J. Brosz, F. Maurer, and M. Boyes. 2016. Datathons: An Experience Report of Data Hackathons for Data Science Education. In SIGCSE '16. ACM, 615-620.

[2] S. Barab and K. Squire. 2004. Design-Based Research: Putting a Stake in the Ground. F. of the Learning Sciences 13, 1 (Jan. 2004), 1-14.

[3] G. Briscoe and C. Mulligan. 2014. Digital Innovation: The Hackathon Phenomenon. Technical Report 6. Creativeworks London.

[4] The Economist. 2015. What the Hack? - The Rise of Hackathons. The Economist (Dec. 2015).

[5] A. Fowler. 2016. Informal STEM Learning in Game Jams, Hackathons and Game Creation Events. In GfH\&GC '16. ACM, 38-41.

[6] MLH. 2016. HACKATHON DATA - Hackcon IV.

[7] D. Munro. 2015. Hosting Hackathons a Tool in Retaining Students with Beneficial Side Effects. 7. Comput. Sci. Coll. 30, 5 (2015), 46-51.

[8] A. Nandi and M. Mandernach. 2016. Hackathons As an Informal Learning Platform. In SIGCSE '16. ACM, 346-351.

[9] G. T. Richard, Y. B. Kafai, B. Adleberg, and O. Telhan. 2015. StitchFest: Diversifying a College Hackathon to Broaden Participation and Perceptions in Computing. In SIGCSE '15. ACM, 114-119.

[10] J. Warner and P. J. Guo. 2017. Hack.Edu: Examining How College Hackathons Are Perceived By Student Attendees and Non-Attendees. In ICER '17. ACM, 254-262. 